\title{
Long Working Hours, Poor Sleep Quality, and Non- Officer Task: Determinant Factors of Fatigue Among Indonesian Tugboat Crews
}

Muchtaruddin Mansyur ( $\square$ muchtaruddin.mansyur@ui.ac.id )

Universitas Indonesia, Faculty of Medicine Dept of Community Medicine \& SEAMEO-

RECFON/Nutritional Research Group https://orcid.org/0000-0002-3100-3269

Risna Sagitasari

Universitas Indonesia

Grace Wangge

SEAMEO Regional Center for Food and Nutrition

Astrid Sulistomo

Universitas Indonesia

Aria Kekalih

Universitas Indonesia

Research article

Keywords: Fatigue, tugboat crews, seafarer, working hours, sleep quality, rating

Posted Date: July 8th, 2020

DOl: https://doi.org/10.21203/rs.3.rs-39492/v1

License: (c) (i) This work is licensed under a Creative Commons Attribution 4.0 International License.

Read Full License 


\section{Abstract \\ Background}

Tugboat crews are susceptible to fatigue their 24-hour stay in the working environment even in their rest time. The fatigue experienced by the seafarers contributes to marine accidents and metabolic and cardiovascular diseases which are long-term effects. This study aimed to analyze the association between working hours and fatigue, along with other possible related factors in tugboat crews.

\section{Method:}

This comparative cross-sectional study included 127 tugboat crew members from a randomly chosen tugboat in Samarinda Harbor, Indonesia. Their fatigue levels at work were subjectively measured using the reaction timer and standardized instrument questionnaire. Data on the crews' personal and occupational factors included age, marital status, rating (job position), duration on board, length of seafaring experience, watch system, smoking habit, coffee and alcohol consumption, and working hours. Moreover, sleep quality and levels of stress-related to the family conflict were measured and analyzed using the Pittsburgh Sleep Quality Index (PSQI) and Work-Family Conflict Scale (WCFS), respectively.

\section{Results}

It was found that $40.2 \%$ of the subjects experienced fatigue due to long working hours ( $\geq 72$ hours/week), poor sleep quality, and being non-officer crews, with adj. OR and $95 \% \mathrm{Cl}$ values of $(12.76$; $3.91-41.70)$, (5.84; 1.67-20.47), and (4.38; 1.28-14.92), respectively. However, the variables of crews' characteristics and occupational factors included age, marital status, duration on board, length of seafaring experience, smoking habit, coffee and alcohol consumption were not statistically associated with the crews' fatigue.

\section{Conclusion}

The incidence of fatigue among Indonesian tugboat crews is considerably high. Working hours, sleep quality, and job rating were strongly associated with fatigue in tugboat crews. Working hours monitoring of tugboats crews needs to be improved.

\section{Background}

Fatigue is a reduction in physical and mental capability resulting from physical, mental, or emotional exertion. It may impair nearly all physical abilities, including strength, coordination, decision-making, balance, speed, and reaction time. Fatigue occurs when there is an imbalance between physical and mental strength utilized during activities and the process of recuperation of the body and brain after 
activities [1]. Fatigue is experienced commonly among the general working population every day, with the estimated prevalence being as high as $22 \%$ [2]. Working at sea certainly makes one susceptible to fatigue; therefore, the shipping industry is increasingly concerned about the possible effects of fatigue on personal and operational safety and the general health and wellbeing of workers [2, 3]. Maritime incidence analyses have shown that approximately $80 \%$ of maritime casualties are due to human error [4] and $26 \%$ of shipping incidents are associated with fatigue in seafarers [5]. Moreover, fatigue, especially chronic fatigue, plays a role in the development of metabolic disorders and cardiovascular diseases. Lowgrade chronic inflammation due to chronic fatigue has long-term effects that cause metabolic and endocrine disorders, cardiovascular diseases, autoimmune diseases, and depression [6, 7].

Watchkeeping and short port turnaround time often increase activities with long and irregular working hours [8]. The International Labor Organization and International Maritime Organization (IMO) with Standards of Training, Certification, and Watchkeeping (STCW) have found that the maximum working hours of seafarers is 14 hours per day or 72 hours in seven days [9]. In seafaring, this is often considerably exceeded, especially on ships with frequent port clearances. The International Federation of Transport has reported that $25 \%$ of seafarers suffered from fatigue because of working for more than 80 hours per week [10].

In seafaring, the watch officer's sleeping time depends mainly on the type of watch system they implement. Two types of watch system are usually applied: the 4/8 watch system (4 hours work and 8 hours rest) and $6 / 6$ watch system ( 6 hours work and 6 hours rest). In the $6 / 6$ watch system, seafarers are more likely to feel sleepy during a shift compared to the $4 / 8$ watch system crews, especially in early morning shifts [11]. Seafarers who work in a $4 / 8$ watch system have better sleep efficiency, continuous sleep, and sufficient sleep hours compared to those in a $6 / 6$ watch system [10]. The risk of fatigue also depends on the seafarers' rating as levels have different job demands, causing varying fatigue levels. For example, officers may face high-stress levels due to their comprehensive personnel and material responsibilities, but non-officers face other risks as they are exposed to strenuous physical activities and job demands [12]. As regards the length of service, fatigue is associated with the pressure acquired at work continuously occurring with increasing employment along with the adaptation process, and a shorter duration onboard induced more risk of fatigue compared with a longer-term on board [13]. Dohrmann et al.[14] study found that the fatigue among the ferry shipping crews was associated with work-family conflict and supervisor support. In their study, these two factors were significantly associated with the two sub-dimensions of fatigue, including physical exertion and physical discomfort.

However, Hystad and Eid [3] found no linear relationship between duration at sea and fatigue.

Another factor, irreversible job-related physical factors on the vessel such as noise and vibration influence fatigue both during working hours and during leisure time and decrease the recreational effect during a free time [16].

The high density of cruise ships manoeuvred by tugboats and the geographic condition of the river, which is having a winding path and varying depth levels increases the risk of accidents in the Mahakam River, 
Indonesia. In 2017, the Samarinda Harbormaster had recorded 13 maritime incidents in Mahakam River involving tugboats, varying from grounding to ship burning and collision. The high incidence and lack of investigation as to whether it was related to a human element such as fatigue warrant a preliminary study to determine factors associated with fatigue among tugboat crews.

\section{Methods}

\section{Study Design}

This comparative cross-sectional study aimed to determine factors associated with fatigue in seafarers. This study took place in Samarinda Harbor from May to June 2018 in various shipping companies in Samarinda City. Tugboat crews were the subjects of this study. The purpose of this study was discussed in all the shipping companies prior to the study. Tugboats were selected in cooperation with companies based on their availability following their voyage schedule. Only ships with a 7-days minimum voyage duration were included and randomized. Assuming there were 8-10 crews per tugboat and the minimum sampling size was 126 subjects, researchers included all crews from the 15 tugboats from the randomization, a total of 138 respondents.

\section{Data Collection}

Data collection consisted of two steps. First, prior to sailing, the respondent was provided with a log sheet of work-rest time to be filled during their voyage. Researchers waited until all the respondents returned from a minimum 7-day cruising. A total of 127 respondents returned from sailing and complied with the second step, i.e., collection of other related data such as age, marital status, smoking habit, caffeine and alcohol intake, and work-related data such as rating, watch system, length of seafaring experience, and duration on board. This study categorized the rating as officer and non-officer,the watch system as $4 / 8$ or $6 / 6$. the length of seafaring experience and the duration on board were asked as open-ended questions. The total working hours per week and hours of sleep per day from the log sheet of work-rest time was obtained. The voyage memo was used to cross-check the log sheet data in order to limit recall bias in maintaining data accuracy. Subjective sleep quality data was assessed using the Pittsburg Sleep Quality Index (PSQI) consisting of self-rated questions along with seven components: subjective sleep qualities, sleep latency, sleep duration, sleep efficiency, sleep disturbance, use of sleep medication, and daytime dysfunction. Scores higher than 5 points indicate poor sleep quality. The PSQI has been validated in the Indonesian language with satisfactory validity and reliability [16].

Work-family conflict was evaluated using the Work-Family Conflict Scale (WFCS), with higher scale scores indicating a higher conflict. For this study, the conflict score was categorized as "yes" and "no" and the median value of the scale was used to determine the cutoff point for categorization.

The fatigue level was determined using two instruments: the reaction time test (reaction timer type L77/Lakassidaya) and standardized questionnaire for the subjective measurement of fatigue at work adopted from the Japan Industrial Fatigue Research Committee and previously validated in the 
Indonesian language with satisfactory validity and reliability [17]. Participants were asked to think about how they felt and then rate 17 questions on a 3-grade response scale with a score of 0 representing "Never;" score of 1, "Yes, Seldom;" and a score of 2, "Yes, Often." Fatigue was characterized by a total score higher than 17 points. In this study, fatigue was determined with the combined value of prolonged reaction time more than 240,000 milliseconds and subjective fatigue score above 17 points.

During the data collecting, this study keeps the daily routines of the participants as a usual to control the objective and subjective measurements' bias. Participants have an informed consent before participating in the study and were assured their answers are kept confidential. The Research Ethics Committee of the Faculty of Medicine, Universitas Indonesia approved this study with the protocol no; 18-05-0563 and approval reference no; 0907/UN2.F1/ETIK/2018.

\section{Statistical Analysis}

Data were analyzed using SPSS for Windows (version 20.0). Continuous variables as the length of seafaring experience and duration on board were expressed as the mean/median ( $\underline{t}$ standard deviation/min-max), and median values were used as cutoff points for categorization of the varying outcomes. The fatigue level was the dependent variable, whereas the others were independent variables. Categorical independent variables were analyzed using the chi-square test, except for age as continuous not normally distributed data were analyzed using the Mann-Whitney test. Results from the bivariate analysis having a $p$-value of $<0.25$ were included as candidate variables for multivariate analysis. Multinomial logistic regression analysis was done to obtain the adjusted odds ratio of determinant factors.

\section{Results}

From the 138 respondents selected from the previous sampling, nine crews from 1 tugboat had a prolonged voyage, making it impossible for them to continue participating in this study. Moreover, a respondent could not participate further due to sickness while on board, and one other had to leave the ship for a family reason; hence, they were excluded from this study. In total, there were 127 participants, consisting of 57 respondents from a group of seafarers working more than 72 hours per week and 70 respondents from a group of seafarers working less than 72 hours per week. The crews' ages were on the range of 21-60 years old. More than half of them were not married $(51.2 \%)$ and smokers $(63 \%)$ and consumed coffee $(53.5 \%)$ and/or alcohol $(22.8 \%)$. More than $75 \%$ of respondents had poor sleep quality, and $54.3 \%$ had hours of sleep less than 7 hours/day, and more than $50 \%$ of respondents experienced work-family conflict.

The study sample comprised of 63 officers (49.6\%) and 64 non-officers (50.4\%), with the majority of respondents using the $4 / 8$ watch system $(82.7 \%)$. Their length of seafaring experience was on the range of $1-35$ years, with $55.9 \%$ of respondents having less than six years of seafaring experience.

Approximately $51.2 \%$ of respondents had less than six months duration on board. Lastly, this study found that $44.9 \%$ of respondents had working hours of more than 72 hours/week. 
Measurement findings showed that $40.2 \%$ of tugboat crews experienced fatigue. From the $59.8 \%$ of nonfatigued crews, $45.7 \%$ had prolonged reaction time, without an increased score on subjective fatigue questionnaire.

Table 1 summarizes results of bivariate analyses using chi-square test. Six variables with $p$-value $<0.25$ were included in multivariate analyses: working hours $(<0.01)$, length of seafaring experience $(0.01)$, sleep quality (0.01), work-family conflict (<0.01), alcohol consumption (0.02), marital status $(0.16)$, and job rating (0.06). 
Table 1

Association of tugboat crews characteristics with the fatigue categories

\begin{tabular}{|c|c|c|c|}
\hline \multirow[t]{2}{*}{ Variable } & \multicolumn{2}{|c|}{ Fatigue; $f(\%)$} & \multirow[t]{2}{*}{$\mathrm{p}$-value } \\
\hline & Yes & No & \\
\hline Age (median; min-max. in years) & $28 ; 20-61$ & $29 ; 20-56$ & $0.76^{m}$ \\
\hline Marital status & $30(46.2 \%)$ & $35(53.8 \%)$ & $0.16^{\mathrm{cs}}$ \\
\hline - No & $21(33.9 \%)$ & $41(66.1 \%)$ & \\
\hline \multicolumn{4}{|l|}{ - Yes } \\
\hline Smoking habit & $9(42.9 \%)$ & $12(57.1 \%)$ & $0.60^{\mathrm{cs}}$ \\
\hline - Medium smoker & $25(42.4 \%)$ & $34(57.6 \%)$ & $0.52^{\mathrm{cs}}$ \\
\hline - Light smoker & $17(36.2 \%)$ & $30(63.8 \%)$ & Reference \\
\hline \multicolumn{4}{|l|}{ - Non smoker } \\
\hline Caffeine consumption & $5(35.7 \%)$ & $9(64.3 \%)$ & $1.00^{f}$ \\
\hline - > 2 cups/day & $25(46.3 \%)$ & $29(35.7 \%)$ & $0.25^{\mathrm{cs}}$ \\
\hline$-1-2$ cups/day & $21(35.9 \%)$ & $38(64.4 \%)$ & Reference \\
\hline \multicolumn{4}{|l|}{ - No } \\
\hline Alcohol consumption & $17(58.6 \%)$ & $12(41.4 \%)$ & $0.02^{\mathrm{cs}}$ \\
\hline - Yes & $34(34.7 \%)$ & $64(65.3 \%)$ & \\
\hline \multicolumn{4}{|l|}{ - No } \\
\hline Sleep quality & $45(46.9 \%)$ & $51(53.1 \%)$ & $0.01^{\mathrm{cs}}$ \\
\hline - Poor & $6(19.4 \%)$ & $25(80.6 \%)$ & \\
\hline \multicolumn{4}{|l|}{ - Good } \\
\hline Hours of Sleep & $38(55.1 \%)$ & $31(44.9 \%)$ & $<0.01^{\mathrm{cs}}$ \\
\hline$-<7$ hours/day & $13(22.4 \%)$ & $45(77.6 \%)$ & \\
\hline \multicolumn{4}{|l|}{$-\geq 7$ hours/day } \\
\hline Work-Family Conflict & $35(54.7 \%)$ & $29(45.3 \%)$ & $<0.01^{\mathrm{cs}}$ \\
\hline - Yes & 16 (25.4\%) & 47 (74.6\%) & \\
\hline - No & & & \\
\hline
\end{tabular}

$\mathrm{m}=$ Mann-Whitney-U test 


\begin{tabular}{|c|c|c|c|}
\hline \multirow[t]{2}{*}{ Variable } & \multicolumn{2}{|c|}{ Fatigue; f (\%) } & \multirow[t]{2}{*}{ p-value } \\
\hline & Yes & No & \\
\hline Watch system & $9(40.9 \%)$ & $13(59.1 \%)$ & \multirow[t]{3}{*}{$0.94^{\mathrm{cs}}$} \\
\hline$-6 / 6$ & $42(40.0 \%)$ & $63(60 \%)$ & \\
\hline \multicolumn{3}{|l|}{$-4 / 8$} & \\
\hline Rating & $20(31.7 \%)$ & $43(68.3 \%)$ & \multirow[t]{3}{*}{$0.06^{c s}$} \\
\hline - Officer & $31(48.4 \%)$ & $33(51.6 \%)$ & \\
\hline \multicolumn{3}{|l|}{ - Non Officer } & \\
\hline Duration on board & $28(43.1 \%)$ & $37(56.9 \%)$ & \multirow[t]{3}{*}{$0.49^{c s}$} \\
\hline$-\leq 6$ months & $23(37.1 \%)$ & $39(62.9 \%)$ & \\
\hline \multicolumn{3}{|l|}{ - > 6 months } & \\
\hline Length of seafaring experience & $36(50.7 \%)$ & $35(49.3 \%)$ & \multirow[t]{3}{*}{$0.01^{\mathrm{cs}}$} \\
\hline$-\leq 6$ years & $15(26.8 \%)$ & $41(73.2 \%)$ & \\
\hline \multicolumn{3}{|l|}{$->6$ years } & \\
\hline Working hours & $40(65.3 \%)$ & $17(34.7 \%)$ & \multirow[t]{3}{*}{$<0.01^{\mathrm{cs}}$} \\
\hline - > 72 hours/week & $11(24.4 \%)$ & $59(75.6 \%)$ & \\
\hline - $\leq 72$ hours/week & & & \\
\hline $\mathrm{m}=$ Mann-Whitney-U test & & & \\
\hline
\end{tabular}

cs $=$ Chi-Square test

Finally, the results of the multivariate analyses focused on three determinant variables, as summarized in Table 2. Working hours more than 72 hours/week were highly associated with fatigue (adj. OR $=12.76$, 95\% Cl; 3.91-41.70), and a significant association between fatigue and sleep quality (adj. OR $=5.84$, $95 \% \mathrm{Cl} ; 1.67-20.47)$ was noted. Non-officer respondents had a higher risk of fatigue compared with the officer respondents (adj. OR $=4.38,95 \% \mathrm{Cl} ; 1.28-14.92$ ). 
Table 2

The determinant factors of fatigue among the seafarer

\begin{tabular}{|llll|}
\hline Variable & \multicolumn{2}{l}{ Fatigue; $f(\%)$} & Adj.OR (95\% Cl) \\
\hline & Yes & No & \\
\hline Working hours & $40(65.3 \%)$ & $17(34.7 \%)$ & $12,76(3.91-41.70)$ \\
$->72$ hours/week & $11(24.4 \%)$ & $59(75.6 \%)$ & \\
$\leq 72$ hours/week & & & \\
\hline Sleep quality & $45(46.9 \%)$ & $51(53.1 \%)$ & $5.84(1.67-20.47)$ \\
- Poor & $6(19.4 \%)$ & $25(80.6 \%)$ & \\
- Good & & & \\
\hline Rating & $31(48.4 \%)$ & $33(51.6 \%)$ & $4.38(1.28-14.92)$ \\
- Non-Officer & $20(31.7 \%)$ & $43(68.3 \%)$ & \\
- Officer & & & \\
\hline R & & & \\
\hline
\end{tabular}

Adj.OR: Adjusted Odd Ratio, adjusted by; hours of sleep, length of seafaring experience, marital status, alcohol consumption, and work-family conflict.

\section{Discussion}

This study found that the fatigue prevalence among tugboat crews in Samarinda Harbor was $40.2 \%$. The related factors were long working hours (particularly those exceeding 72 hours/week), sleep quality, and rating.

The high prevalence of fatigue among our subjects was slightly lower than its prevalence among the floating crane ship crews reported in a study (69.4\%) [18]. This difference might be due to variations in the work system characteristics between these two ship crews. Compared to a tugboat, a floating crane likely stays in one place for a more extended period because of its work nature, and no chance of getting off the ship to ward off boredom induces a more monotonous working rhythm in ship crews [15]. Whereas on a tugboat, although the entire sailing time may be longer, in conditions where the ship has to wait for loading and unloading, the crew may get off the boat to shop for food and needs on board or to banish boredom. Boredom effects contributed the most to the performance of the crew [19].

This study found differently of the factor of work-family conflict with the Dohrmann et al.'s study [14]. Having been adjusted with some variables -hours of sleep, length of seafaring experience, marital status, alcohol consumption-, the work-family conflict variable was not significantly associated with the tug boat 
crews' fatigue. This non-significant association may be explained by the fact that in our study, the fatigue was not differentiated by physical and mental dimension, but we used the combination of both of them.

Huanxin [20] and Jepsen [21] reported that chronic fatigue is due to the accumulation or repetition of acute fatigue. Smith [22] stated that several job conditions may cause acute and chronic fatigue and may decrease awareness and cumulate sleep debt, including night shift work. Moreover, Lacourt et al. [5] argued that persistent fatigue associated with chronic low-grade inflammation is increased by the working condition, including night shift work. Furthermore, Chen et al. [6] noted that chronic low-grade inflammation could lead to various prolonged stress-related disorders such as cardiovascular disease, diabetes, autoimmune conditions, and even clinical depression. Therefore, the high prevalence of fatigue among seafarers should be prevented and controlled by looking into the determinant factors enumerated in this study.

This study found that working hours was significantly associated with fatigue (adj. OR $=12.76,95 \% \mathrm{Cl}$; $3.91-41.70$ ). More than $40 \%$ of the study subjects had working hours more than 72 hours/week, exceeding the seafarer working hour limit of the STCW-IMO 2010 regulation [8]. This study supports the finding of Salyga [22] who used passenger ship crews as study subjects. Generally, passenger ships use the automation system in their daily operation that helps minimize the fatigue experienced by seafarers.

This study showed that $75.6 \%$ of respondents had poor sleep quality, significantly increasing the risk of fatigue (adj. OR $=5.84,95 \% \mathrm{Cl} ; 1.67-20.47$ ). A similar finding was reported by Andhika [18] that is, respondents with poor sleep quality had a considerable chance of experiencing fatigue. Smith et al. [9] also obtained a corresponding result that poor sleep quality was significantly related to fatigue. Watchkeeping duty, especially at night, disturbs sleep, making it challenging to maintain good sleep quality [21]. Smith and McNamara [24] found that sleep quality was affected by noise and movement of the ship and reported that $44 \%$ of respondents considered noise as a nuisance. The tugboat crew's cabins are generally at the same level as the engine room. This could explain why this study's subjects experienced sleep disturbance due to engine noise exposure.

This study also found that there was a significant association between job rating and fatigue level and that non-officers had a higher risk of fatigue than officers ( $\mathrm{OR}=4.38$ with $95 \% \mathrm{Cl} ; 1.28-14.92)$. Same as in Andhika's study [18], it was found that on a floating crane, non-officer crews experienced more fatigue than officers. Smith et al. [9] also stated that non-officers have a high workload due to their function as technical operators and do more heavy physical activities with longer work hours compared to officers. Burke [25] found that officer crews had relatively more regular shifts and working hours than non-officers. Hence, the risk of fatigue of non-officers is higher than that of officers [20] [25].

The limitations of this study included no direct observation during work-rest time recording. Additionally, data of work-rest time depended solely on the respondents' answers on the self-completed questionnaire. Nevertheless, bias was minimized by cross-checking with the voyage memo. Fatigue assessment is also needed, considering what Volker et al. [26] mentioned that there are no existing agreed-upon methods to detect and quantify neither fatigue nor a robust diagnostic tool to measure subjective fatigue. This study 
setting is limited to the tugboat crews, nevertheless the results of this study might be generalized to other various ships' crew with the similar personal characteristics, their tasks as seafarer, and their working environment.

\section{Conclusion}

The prevalence of fatigue among tugboat crews in Samarinda is relatively high. Fatigue is significantly associated with working hours and quality of sleep with the rating.

\section{Recommendation}

Workers should improve their knowledge and awareness regarding fatigue and its related factors. Crews should start practising a healthy lifestyle such as avoiding smoking and alcohol, consuming a balanced diet on board, exercising regularly, and enhancing sleep quality through sleep hygiene or strategic nap.

The government especially the harbourmaster should look into the importance of monitoring working hours in maintaining health and safety on board, raising awareness among stakeholders on the dangers of fatigue in the workplace due to prolonged and irregular working hours and lack of sleep on board. Marine companies are encouraged to conduct screenings regarding fatigue and to hold sleep disturbance management sessions in collaboration with health and safety institutions.

Also, marine companies should start developing a fatigue risk management system and fatigue and working hours monitoring as strategies to mitigate fatigue in marine life, promoting wellness programs for crew members on board and enhancing sleep quality by improving ship accommodation facilities and maintaining good housekeeping.

\section{Abbreviations}

Adj.OR

adjusted odds ratio

cS

Chi-Square test

IMO

International Maritime Organization

$\mathrm{m}$

Mann-Whitney-U test

PSQI

Pittsburg Sleep Quality Index

$\mathrm{R}^{2}$

Coefficent of Determinant

SCTW 
Standards of Training, Certification, and Watchkeeping

WFCS

Work-Family Conflict Scale

\section{Declarations}

\section{Ethics approval and consent to participate}

The Research Ethics Committee of the Faculty of Medicine Universitas Indonesia/Cipto Mangunkusumo National Hospital, approved this study with approval number; 0907/UN2.F1/ETIK/2018. All participants have had both written and verbal study information and agreed to participate in the study by signing the written informed consent.

\section{Consent for publication}

All authors have approved the submission of this paper, and it is not under consideration by any other journal.

\section{Availability of data and material}

The datasets used and/or analysed during the current study available from the corresponding author on reasonable request

\section{Competing interests}

All contributing authors declare no conflict of interest.

\section{Funding}

The authors received funding support from the Directorate of Research and Community Development Universitas Indonesia through the 2018 research funding No. 5282/UN2.R3.1/HKP 05.00/2018. The funding agency had a role in review the study proposal at the selection phase.

\section{Authors' contributions}

MM; conceptualize, study design \& method, formal analysis, supervision, manuscript writing

RS: conceptualize, study design \& method, data collecting, manuscript drafting

GW: study design \& method, manuscript writing

AS: study design \& method, manuscript writing

AK: study design \& method, manuscript writing

\section{Acknowledgement}


We express our gratitude to Harbor Master of Samarinda Harbor, Port Health Office of Samarinda, and the marine companies for their valuable support, and I thank all crew members for participating in this study.

\section{References}

[1] International Maritime Organization. Guidance on fatigue mitigation and management. vol. MSC/Circ.1. 2001.

[2] Wadsworth EJK, Allen PH, McNamara RL, Smith AP. Fatigue and health in a seafaring population. Occup Med (Chic III) 2008;58:198-204. doi:10.1093/occmed/kqn008.

[3] Hystad SW, Eid J. Sleep and Fatigue among Seafarers: The role of environmental stressors, duration at sea and psychological capital. Safety and health at Work 2016; 7: 363-71

[4] Guedes Soares, C. \& Teiseira AP. Risk assessment in maritime transportation. Reliab Eng Syst Saf 2001;74:299-309.

[5] Gander PH. Sleep and sleepiness in fishermen on rotating schedules. Chronobiol Int 2008;25: 389-398.

[6] Lacourt TE, Vichaya EG, Chiu GS, Dantzer R and Heijnen CJ. The high costs of low-grade inflammation: persistent fatigue as a consequence of reduced cellular-energy availability and nonadaptive energy expenditure. Front Behav Neurosci 2018;12:78 https://doi.org/10.3389/fnbeh.2018.00078

[7] Chen L, Deng H, Cui H, Fang J, Zuo Z, Deng J, Li Y, Wang X, Zhao L. Inflammatory responses and inflammation-associated diseases in organs. Oncotarget 2018; 9: 7204-7218.

[8] Oldenburg M, Jensen HJ, Latza U, Baur X. Seafaring stressors aboard merchant and passenger ships. Int J Public Health 2009;54:96-105. doi:10.1007/s00038-009-7067-z.

[9] International Transport Workers Federation. STCW: A Guide for seafarers - taking into account the 2010 Manila amendments. London: International Transport Workers Federation; 2010,p.64

[10] Smith A, Allen P, Wadsworth E. Seafarer fatigue: the Cardiff Research Programme. Occup Heal Psychol 2006:1-87.

[11] Harma M, Partinen M, Repo R, Sorsa M. Effects of $6 / 6$ and 4/8 watch systems on sleepiness among bridge officers. Chronobiol Int 2008;25:413-23.

[12] Kongsvik T, Størkersen K, Hansen JH. The possible impact of different watch keeping regimes at sea on sleep, fatigue, and safety. 2012: p1-8. doi:10.1201/b11433-413.

[13] Smith AP, Allen PH, Wadsworth EJ. A Comparative approach to seafarers' fatigue. Researchgate 2015:1-15. 
[14] Dohrmann, S.B., Herttua, K. \& Leppin, A. Fatigue in ferry shipping employees: the role of work-family conflict and supervisor support. BMC Public Health 19, 1693 (2019). https://doi.org/10.1186/s12889019-7954-z

[15] Hystad SW, Eid J. Sleep and Fatigue Among Seafarers: The role of environmental stressors, duration at sea and psychological capital. Saf Health Work 2016;7:363-71. doi:10.1016/j.shaw.2016.05.006.

[16] Alim IZ. Uji validitas dan reliabilitas instrumen Pittsburgh Sleep Quality Index versi Bahasa Indonesia. Universitas Indonesia, 2015: p71-73.

[17] Setyawati L, Kusumaharta, Prawirohusodo S. Kelelahan kerja kronis: Kajian terhadap perasaan kelelahan kerja, penyusunan alat ukur serta hubungannya dengan waktu reaksi dan produktivitas kerja. Universitas Gadjah Mada, 1998.

[18] Andhika A. Analisis Faktor Risiko Kelelahan Kerja pada Kru Kapal Floating Crane di Area Operasional PT. X. Universitas Indonesia 2016: p.75-81.

[19] Nurahaju R, Utami DN. Factor analysis of Seafarers Performance. International Journal of Advanced Research 2019;7(100: 1318-1332. DOI: 10.21474/IJAR01/9961

[20] Wang H. Study on Assessment of Seafarer's Fatigue. World Maritime University 2012: P.18-24.

[21] Jepsen JR, Zhao Z, Van Leeuwen WMA. Seafarer fatigue: a review of risk factors, consequences for seafarers' health and safety and options for mitigation. Int Marit Health 2015;66:106-17. DOI:10.5603/IMH.2015.0024.

[22] Smith A. Adequate crewing and seafarers' fatigue: The International Perspective. London: 2006: p.2729.

[23] Salyga J, Kušleikaite M. Factors influencing psychoemotional strain and fatigue, and relationship of these factors with health complaints at sea among Lithuanian seafarers. Medicina (B Aires) 2011;47:67581.

[24] Smith, AP, and McNamara, RL. Noise and disturbed sleep aboard ships and on oil installation. Paper presented at the 31st International Congress on Noise Control Engineering, Dearborn, Michigan 2002.

[25] Burke, A., Ellis, N., Allen, P. The impact of work patterns on stress and fatigue among offshore worker populations. In McCabe, P. T. (Ed.), Contemporary ergonomics 2003: 131-136). London, UK: Taylor \& Francis.

[22] Volker I, Kirchner C, Bock OL. Relation between multiple markers of work-related fatigue. safety and health at work 2016; 7:124-129.

\section{Supplementary Files}


This is a list of supplementary files associated with this preprint. Click to download.

- STROBEchecklistFatigueamongtugboatcrews.docx 